\title{
Influence of FRP Reinforcement Ratio on Flexural Behavior of Concrete One-Way Slabs
}

\author{
Alaa Taha ${ }^{1}$, Yousef Rihan ${ }^{1}$, Wael Alnahhal ${ }^{2}$
}

\begin{abstract}
This paper presents an experimental study on the flexural behavior and ultimate capacity of reinforced concrete (RC) one-way slabs reinforced with FRP bars. Flexural tests were performed on four concrete one-way slab specimens that were loaded until failure. The main parameters in the conducted experiment were the reinforcement type (Basalt FRP bars, and Glass FRP bars), and the reinforcement ratio $\left(1.4 \rho_{f b}\right.$ and 2.8 $\rho_{f b}$ ). The one-way slabs' mid-span deflection and compressive strain were measured and recorded. The test results showed that the increase in the reinforcement ratio improved the flexural capacity of the one-way slabs significantly. Moreover, the oneway slabs with GFRP bars as reinforcement recorded slightly higher flexural capacity than that of BFRP bars as reinforcement. The test results obviously indicated that both Basalt FRP and Glass FRP bars can be used as an alternative construction material.
\end{abstract}

Keywords-Flexural Behavior, Basalt FRP Bars, Glass FRP bars, One-way Slabs.

\section{Introduction}

The Gulf region and particularly Qatar suffers from severe weather conditions. Qatar's harsh environmental conditions, such as the extreme temperature, the severe humidity, and the presence of high chloride content in the soil are factors that lead to corrosion of the steel reinforcement, deterioration, and cracks in the typical reinforced concrete. This severe environmental conditions exposure causes rapid deterioration and reduces the sustainability of conventional reinforced concrete (RC) infrastructure. However, with the evolution of material science, the fiber reinforced polymer (FRP) material is becoming a promising alternative to the currently used construction materials. The FRP are promising to be the future of construction materials due to their outstanding durability against corrosion, easy workability for in-situ applications and improved weight-to-strength ratios in reference to their counterpart traditional materials. Carbon, Glass and Aramid FRP are the most commonly used FRPs in the industry. Glass FRP (GFRP) is the most frequently used FRP in Civil Engineering applications. Knowing that, stress corrosion and creep failure are what the GFRP usually affected by. Therefore, a more recent FRP material called basalt FRP (BFRP) have been developed to be used as an alternative to the conventional steel reinforcement with a price of \$2.5-5.0 per $\mathrm{kg}$ [1] That is comparable to the Glass FRP and remarkably lower than carbon fiber materials.

\footnotetext{
1 Graduate Student, Department of Civil and Architectural Engineering, Qatar University, Qatar.

2 Assistant Professor, Department of Civil and Architectural Engineering, Qatar University, Qatar. Corresponding Author.
}

Although there is no particular limit for their shape, FRPs are mostly used for reinforcing the structural members instead of steel reinforcement in Civil Engineering applications. The BFRP bars are well-known for their resistance to corrosion, having more ductile behavior at failure than carbon fibers, and of being more efficient than glass fiber at chemical resistance in alkaline environment [2-6]. In the contrary, there have been some studies that reported BFRP bars to be poor in alkali resistance [7]. Many design guidelines have been introduced by numerous studies to develop National standards for the design and construction of structures made of FRC and are available in USA, Canada, and Japan [8-11]. However, the documents available do not contribute to particular standards for the design and construction of BFRP bars structural reinforced concrete. Consequently, basalt discrete fibers are known to be materials that are environmentally friendly which are manufactured from volcanic rocks by a process that involves melting similar to that done for glass fibers. Also, the production process of basalt fiber does not involve any additives which is an advantage over the glass fibers with regards to the cost [12].

Fluctuations occur in the properties of basalt fiber due to the variations in its production process and minerals that the basalt fiber is composed of. That is why it is essential to perform extensive experimental tests on the BFRP product in order to determine its mechanical components due to its critical effect on the properties of basalt fiber. Compared to steel reinforcing bars, FRP bars have a low modulus of elasticity which affects the elastic performance of FRP bars, this contributes to large cracks' width and high deflections of FRP reinforced concrete structures. The BFRP bars' modulus of elasticity is four times less than that of steel bars leading to higher deformations to result in beams that are reinforced with BFRP bars once compared to beams reinforced with conventional steel [13]. Therefore, this makes the serviceability limit state critical factor that needs to be monitored.

This study will investigate the effect of the main reinforcement type and ratio on the flexural performance of concrete one-way slabs reinforced with FRP bars.

\section{The Experimental Program}

The experimental program consists of two parts: (a) the material characterization tests, in which the compressive and the flexural tensile strengths of concrete cylinders and prisms were tested and determined. In addition, the tensile strength of the FRP bars was determined; (b)one-way slab tests, in which monotonic tests were done on $\mathrm{RC}$ one-way slabs reinforced with FRP bars along with the control specimens. 


\section{A. Mix Ingredients and Materials}

The cement type used in the concrete mix was Portland cement. The coarse aggregates used were the gabbro aggregates with particles retaining at $4.75 \mathrm{~mm}$ sieve. Sand was used as fine aggregates with particles retaining at $0.075 \mathrm{~mm}$ sieve. CHRYSO Fluid CQ 515 which is the admixture used to increase the workability of the concrete mix. The target strength of concrete after 28 days was 35 MPA. The weight proportions of all ingredients are shown in Table 1.

Table 1: Weight Proportions of the Concrete Mix

\begin{tabular}{cc}
\hline Ingredients & Weight Proportion \\
\hline Cement & 1.00 \\
Water & 0.49 \\
Coarse Aggregate & 2.96 \\
Fine Aggregate & 2.0 \\
\hline
\end{tabular}

\section{B. Compression and Flexural Tensile Strengths Tests}

The flexural test was performed in accordance with ASTM C 78 where three test prisms are used from each concrete mix with a dimension of $100 \times 100 \times 500 \mathrm{~mm}$. The flexural tensile strength was determined using the average strength of the three prisms in each concrete batch. The compressive strength was evaluated by using three standard concrete cylinders from each concrete batch that are $150 \mathrm{~mm}$. in diameter and $300 \mathrm{~mm}$. in height and the test was done in accordance with ASTM C 39. The average of compressive strength of the three cylinders was considered the compressive strength of concrete.

\section{Tensile Strength of FRP Bars}

This test was used to determine the tensile strength and modulus of elasticity of FRP reinforcing bars. According to ASTM D7205, the tensile strength of FRP bars is performed by holding an FRP bar by the tensile test machine after putting it inside a steel cylinder filled with poly-vinyl chloride (PVC) as showed in Figures 1 and 2, That is because FRP bars is anisotropic material where they are very weak in compression in the transverse direction.

\section{Large-Scale One-way slabs Flexural Tests}

The dimensions of the one-way slabs used for the flexural tests are $2550 \mathrm{~mm}$. in length $\times 500 \mathrm{~mm}$. in width $\times 175 \mathrm{~mm}$. in height, as shown in Figure 3. For comparison purposes, the one-way slabs specimens were reinforced with either BFRP or GFRP bars as bottom (main) reinforcement that compose the tension side. All the one-way slab specimens were loaded until failure with four-point loading using the Instron 1500-HDX static hydraulic universal testing machine which belongs to the structural laboratory of Qatar University. The mid-span deflections of the one-way slabs were measured using LVDTs. $50 \mathrm{~mm}$ length specialized strain gauges were used for measuring the strains of the concrete.

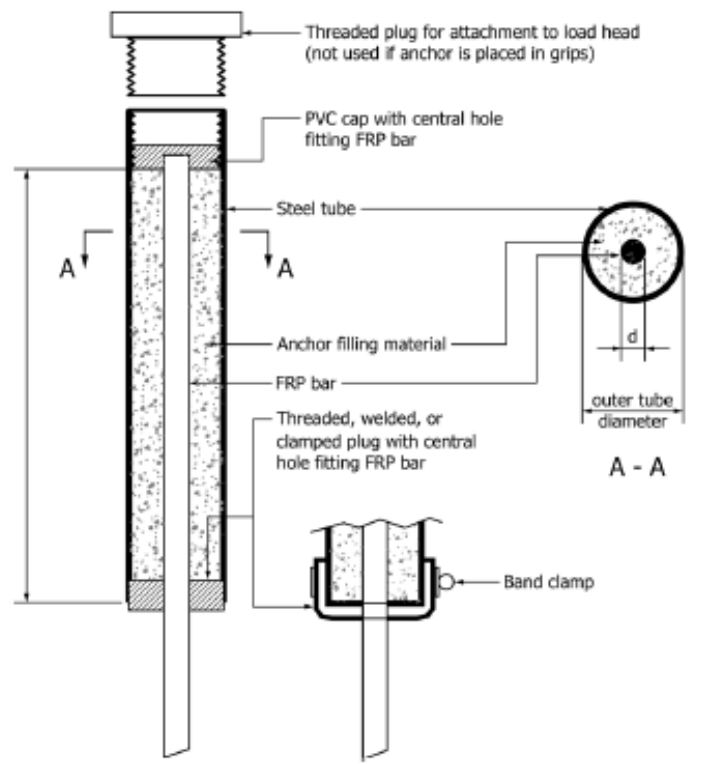

Figure 1. Handling System of FRP Reinforcing Bars for Tensile Strength Test. (ASTM D7205/D7205M-06 [16])

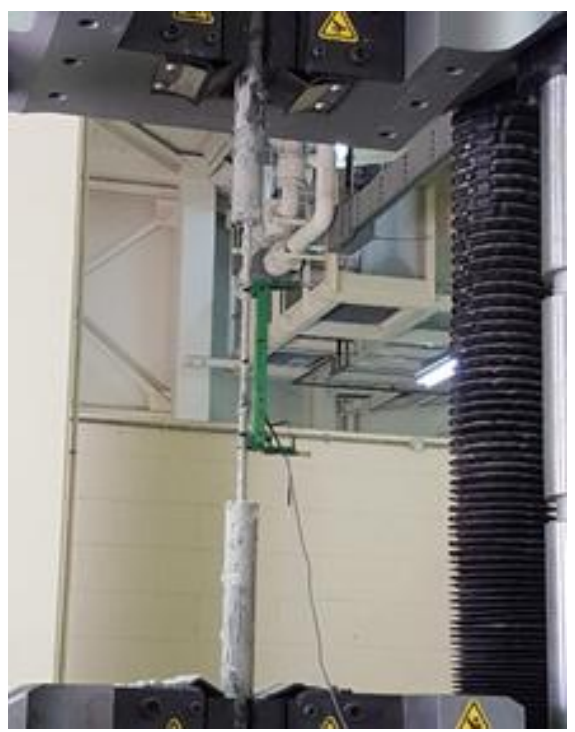

Figure 2. FRP Reinforcing Bar under Tensile Strength Test.

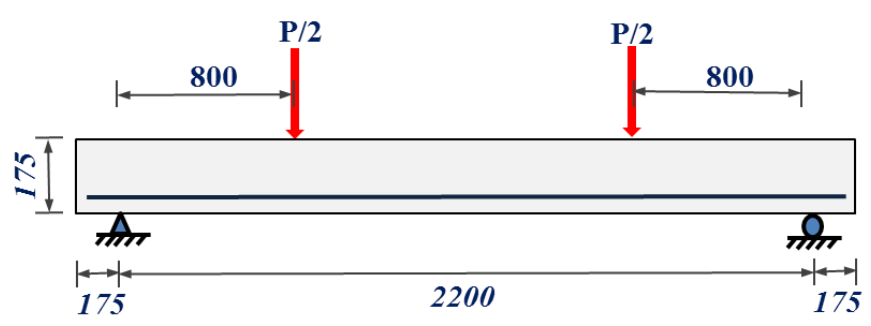

Figure 3: Large-Scale One-Way Slab Layout. (Dimensions in mm) 
ISBN: 978-1-63248-139-9 doi: 10.15224/ 978-1-63248-139-9-32

\section{Tests Results and Discussion}

\section{A. Compressive and Flexural Tensile Test Results}

Table 1 shows the measured compressive and flexural tensile strengths of the concrete mixes.

Table 1: Average Compressive and Flexural Tensile Strengths Test Results.

\begin{tabular}{|c|c|c|c|c|}
\hline $\begin{array}{c}\text { Sample } \\
\text { No. }\end{array}$ & $\begin{array}{l}\text { Comp. } \\
\text { Strength } \\
\text { (MPa) }\end{array}$ & $\begin{array}{l}\text { Aver. } \\
\text { (MPa) }\end{array}$ & $\begin{array}{c}\text { Flexural } \\
\text { Strength } \\
\text { (MPa) }\end{array}$ & $\begin{array}{l}\text { Aver. } \\
\text { (MPa) }\end{array}$ \\
\hline 1 & 38.6 & \multirow{3}{*}{39.31} & 3.84 & \multirow{3}{*}{3.74} \\
\hline 2 & 39.1 & & 3.73 & \\
\hline 3 & 40.22 & & 3.66 & \\
\hline
\end{tabular}

\section{B. Tensile Strength of FRP Bars Results}

The tensile strength test of GFRP reinforcing bars was continued until GFRP reinforcing bars were failed as shown in Figure 4. The stress-strain diagram for GFRP reinforcing bars is illustrated in Figure 5. The nominal tensile strength and nominal modulus of elasticity of both BFRP and GFRP bars are presented in Table 2.

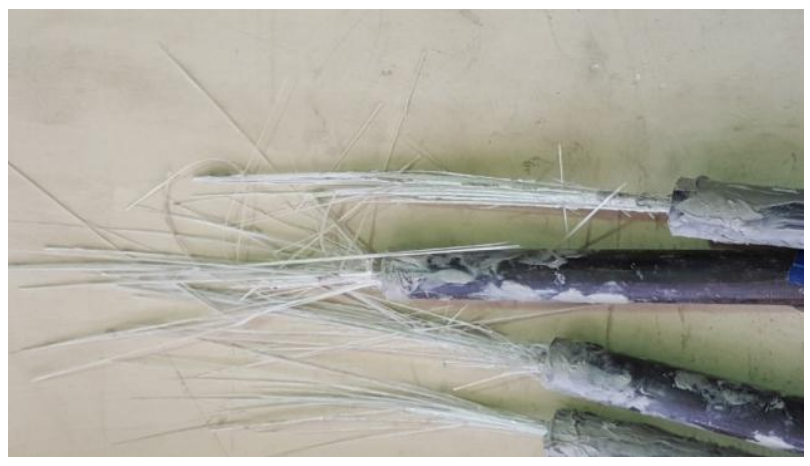

Figure 4. GFRP Reinforcing Bars after Failure.

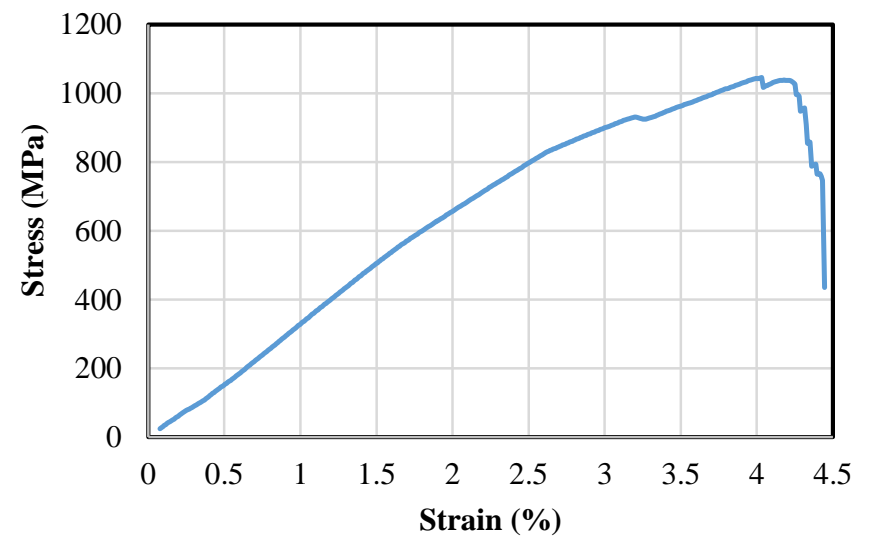

Figure 5. Stress-Strain Diagram of GFRP Reinforcing Bars.
Table 1: Properties of FRP Reinforcing Bars.

\begin{tabular}{|l|c|c|c|}
\hline $\begin{array}{c}\text { Type of } \\
\text { Reinforcement }\end{array}$ & $\begin{array}{c}\text { Yield } \\
\text { Strength } \\
\text { (MPa) }\end{array}$ & $\begin{array}{c}\text { Modulus of } \\
\text { elasticity } \\
\text { (GPa) }\end{array}$ & Surface \\
\hline GFRP & 1060 & 45 & Ribbed \\
\hline BFRP & 1168 & 50 & $\begin{array}{c}\text { Sand } \\
\text { Coated }\end{array}$ \\
\hline
\end{tabular}

\section{One-Way Slab Test Results}

Four one-way slab specimens reinforced with FRP bars were tested and loaded under four-point loads until failure occurred, as shown in Figure 6. The mid-span deflections were recorded.

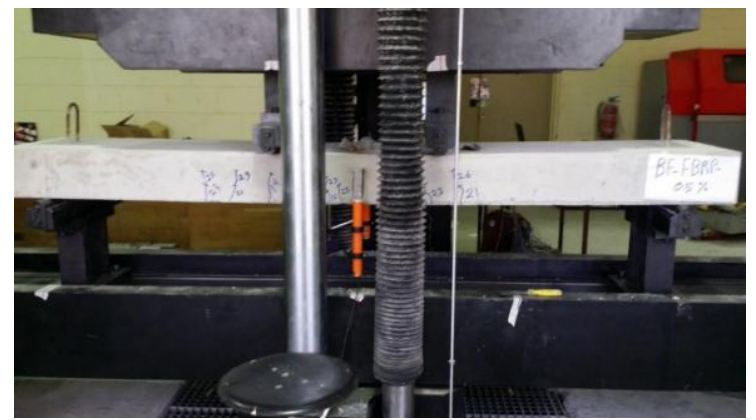

Figure 6 One-Way Concrete Slab during Flexural Test.

Figure 7 shows the load-deflection relationship for oneway slabs reinforced BFRP bars for two different reinforcement ratios: the balanced reinforced ratio $\left(\rho_{\mathrm{f}}=\right.$ $\left.1.4 \rho_{\mathrm{fb}}\right)$, and the over-reinforced ratio $\left(\rho_{\mathrm{f}}=2.8 \rho_{\mathrm{fb}}\right)$. As shown in Figure 7 , the load-deflection relationship of the one-way slab specimens reinforced with BFRP bars is divided into two stages. The first stage is the pre-cracking stage and the second stage is the post-cracking stage. Regarding the deflection behavior in the pre-cracking stage, the relation between the load and the deflection was linear until the appearance of the first crack. Cracking moments were approximately the same because cracking moment depends mainly on concrete. Once the cracks appeared, the deflection started heavily to increase due to small increments in the load applied. The reason behind this change in the load-deflection behavior is the reduction in the stiffness, which in turn depends on the reinforcement ratio of the BFRP bars. Thus, it was noticed from the test results that one-way slabs with higher reinforcement ratio resulted in less reduction in the stiffness, which caused less mid-span deflection to occur. From slopes, it is clear that the overreinforced specimen had more stiffness than the balanced reinforced specimen. The increase in the BFRP reinforcement ratio increased the ultimate load by about $15 \%$ and reduced the deflection by approximately the half. Behaviors of both oneway concrete slabs were brittle because of the brittle nature of BFRP reinforcing bars and concrete mix. Similar behavior was reported for the one-way slab reinforced with GFRP bars as illustrated in Figure 8. 
Proc. of the Sixth International Conference on Advances in Civil, Structural and Environmental Engineering - ACSEE 2017. Copyright ( Institute of Research Engineers and Doctors. All rights reserved.

ISBN: 978-1-63248-139-9 doi: 10.15224/ 978-1-63248-139-9-32

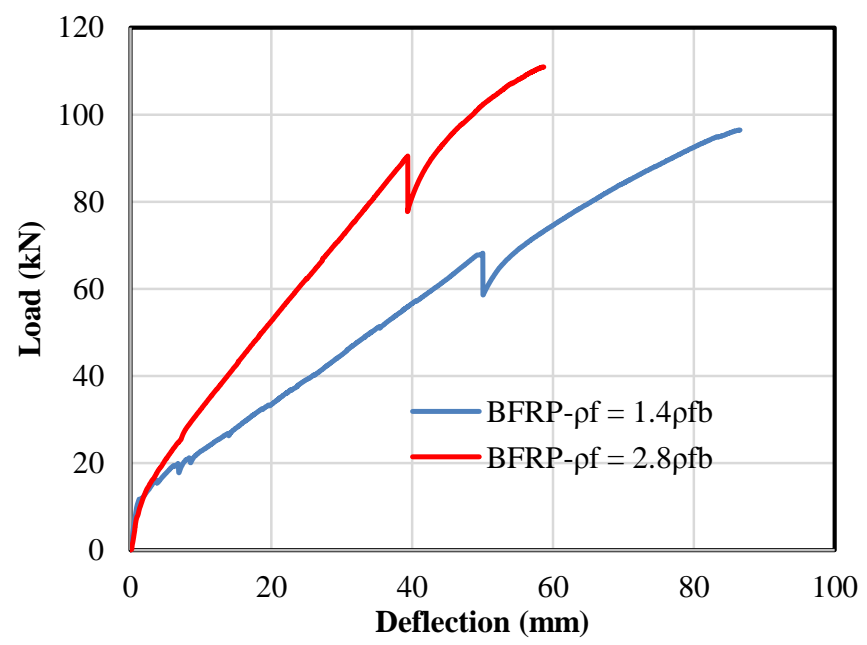

Figure 7: Load-deflection diagram with different BFRP reinforcement ratios

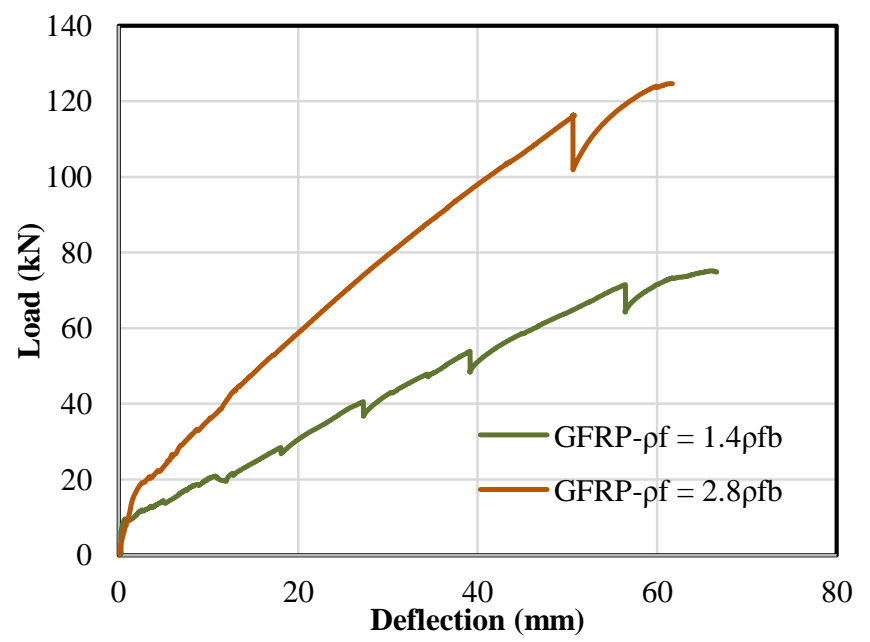

Figure 8: Load-deflection diagram with different GFRP reinforcement ratios

\section{Conclusion}

In conclusion, this paper has examined the effect of the increase in the FRP reinforcement ratio on the flexural properties of RC one-way slabs. The work done led us to the following conclusions:

- $\quad$ The reinforcement ratio has no effects on the cracking moment because before first cracking the only resisting element is the concrete mix.

- $\quad$ The increased reinforcement ratio from $1.4 \rho_{f b}$ to $2.8 \rho_{f b}$ resulted in an increase in the load capacity of RC Oneway slabs with less deflection.

\section{Acknowledgment}

The authors show their gratitude to Qatar Foundation for their financial support through a UREP award no. UREP18162-2-065 from the Qatar National Research Fund.

\section{References}

[1] Kameny Vek. (2010). "Advanced basalt fiber." (http://www.basfiber.com).

[2] Fahmy, M., Wu, Z., and Wu, G. (2009). "Seismic performance assessment of damage-controlled FRP-Retrofitted RC bridge columns using residual deformations." J. Compos. Constr., 10.1061/(ASCE)CC.1943-5614.0000046, 498-513.

[3] Erlendsson, J. O. (2012). "Continuous basalt fiber as reinforcement material in polyester resin." M.S. thesis, School of Science and Engineering at Reykjavík Univ., Reykjavík, Iceland.

[4] Sim, J., Park, C., and Moon, D. J. (2005). "Characteristic of basalt fiber as a strengthening material for concrete structures." Compos. Part B, 36(6), 504-512

[5] Van de Velde, K., Kiekens, P., Van Langenhove, L., Cater, S., (2002). Basalt fibers as reinforcement for composites, Editorial, International Composites News, March 2002.

[6] El Refai, A., Ammar, M., and Masmoudi, R. (2014). "Bond performance of basalt fiber-reinforced polymer bars to concrete. J. Compos. Constr. Vol. 6-80.

[7] Li, H., Xian, G., Ma, M., and Wu, J. (2012). "Durability and fatigue performances of basalt fiber/epoxy reinforcing bars." Proc., 6th Int. Conf. on FRP Composites in Civil Engineering (CICE 2012), Univ. of Rome La Sapienza, Rome.

[8] ACI (American Concrete Institute). (2015). "Guide for the design and construction of structural concrete reinforced with FRP bars." ACI 440.1R-15, Farmington Hills, MI.

[9] ISIS Canada, Reinforcing Concrete Structures with Fiber Reinforced Polymers. Design Manual N8 3 Version 2, Canada ISIS Canada Corporation, Manitoba, 2007.

[10] CSA, S806-12: Design and Construction of Building Components with Fiber-Reinforced Polymers, Canadian Standards Association, Canada, 2012.

[11] Japan Society of Civil Engineers (1997). Recommendation for design and construction of concrete structures using continuous fiber reinforcing materials. Concrete Engineering Series 23; Tokyo, Japan Society of Civil Engineers.

[12] Wei, B., Cao, H., and Song, S. (2010). Environmental resistance and mechanical performance of basalt and glass fibers. Materials Science and Engineering; 527(18-19); 4708-4715]

[13] Marek U., Andrzej L., Andrzej G.(2013). "Investigation on Concrete Beams Reinforced with Basalt Rebar.” Procedia Engineering 57 (2013) $1183-1191$

[14] ReforceTech, AS, www.ReforceTech.com, visited 04/25/2015.

[15] Sudeep Adhikari (2013). Mechanical and structural characterization of MiniBar reinforced concrete beams. Ph. D. Dissertation.

ASTM D7205/D7205M-06, Standard Test Method for Tensile Properties of Fiber Reinforced Polymer Matrix Composite Bars, ASTM International, West Conshohocken, PA, USA, 2011. 